\title{
Generation of Nanostructures by the Aggregation of Porphyrin Derivatives with Long Alkane Chain in Mix-Solvent
}

\author{
Amrita Ghosh, T. Selvamani, D. Amilan Jose, Amitava Das, and I. Mukhopadhyay \\ Central Salt and Marine Chemicals Research Institute, Bhavnagar 364002, Gujarat, India
}

Received 8 February 2007; Revised 20 May 2007; Accepted 31 July 2007

Recommended by Michael S. Wong

Controlled aggregation of tetrakis-(4-(hexadecyl oxy)-phenyl) porphyrin and its copper(II)-complex was studied in mix-solvent system at room temperature. Structure of the aggregates was characterized by scanning electron microscopy (SEM), transmission electron microscopy (TEM), powder X-ray diffraction (XRD), and UV-visible spectroscopy. TEM results indicated the formation of organized nanostructures from the porphyrin derivative and its corresponding copper(II)-complex. XRD results showed that the bulk and nanostructured free porphyrin derivatives had the similar crystalline morphology. UV-visible-NIR spectroscopic data showed broad red-shifted Soret band, indicating JJ aggregation among the monomer units. Conjugate effect of lateral $\pi-\pi$ interaction among the tetrapyrrole cores and hydrophobic interaction among the long alkane chains substituted in the peripheral phenyl rings is believed to lead to the organized nanostructures. Effect of solvent ratio on the aggregate structure is also revealed.

Copyright (C) 2007 Amrita Ghosh et al. This is an open access article distributed under the Creative Commons Attribution License, which permits unrestricted use, distribution, and reproduction in any medium, provided the original work is properly cited.

\section{INTRODUCTION}

Tetraphenylporphyrin, its various derivatives, and related metalloporphyrin complexes have received much attention owing to their important role in biology, solar energy conversion, photonics, and catalysis. Porphyrin molecules are known to form aggregates under certain conditions and this phenomenon has been studied by a number of research groups in the last two decades. Reports reveal that certain tetraaryl-substituted porphyrins tend to aggregate even in homogeneous solution [1]. Among various aggregates reported on porphyrin derivatives, two types of aggregates are found to be very important [2]: the $\mathrm{H}$-aggregates, where the transition dipole moment of monomers is perpendicular to the line connecting their centers (the face-to-face arrangement), and the J-aggregates, in which the transition dipole moment of the monomers is parallel to the line connecting their centers (the side-by-side arrangement) [2]. Various factors are known to influence the aggregate formation of porphyrin molecules in solution, for example, structure and substitution of the porphyrin itself, $\mathrm{pH}$ of the medium, surfactants present, and the ionic strength of the medium $[3,4]$. It has been reported that aggregation of suitably substituted tetraaryl porphyrin can also be promoted by the coplanarity and the zwitterionic nature of the monomer in homogeneous solution [1]. Self-aggregation of cationic meso- tetratolylporphyrin derivatives in aqueous solution is found to be controlled by electrostatic and hydrophobic interactions [3]. Even polymer template like polylysine can also induce efficient formation of J-aggregate to produce ordered rod structure in the micron length scale [5]. Recently, aggregation of porphyrin derivatives have been studied for synthesizing nanostructured materials as well [6-11].

Aggregation of tailor-made substituted porphyrin derivatives has been studied by Gong et al. in mix-solvent systems [6]. It has been reported that the polyhydroxyl compoundbased anti-agglomerating agents covalently bind porphyrin/metalloporphyrin molecules to form stable nanoparticles $[6,7]$. In another work, thin film of self-assembled porphyrin has been achieved by following the method of controlled orientation of the molecular building blocks [8]. Wang et al. have reported the formation of nanotubes based on porphyrin and metalloporphyrin derivatives by ionic self-assembly in aqueous solution [9]. It has been shown that the electrostatic forces between the charge tectonics along with other interactions, like van der Waals, hydrogen bonding, axial coordination, and other weak intermolecular interactions, typically contribute to the stability of the nanostructures. Nakanishi et al. reported a novel reprecipitation method for the synthesis of organic nanocrystals using solvents of different polarity $[10,11]$. In a recently reported work, nanotubes of porphyrin derivatives have been 
synthesized by metal-mediated coordination polymers at the water chloroform interface [12]. Fluorescence microscopic imaging under magnetic field has shown the formation of rod-type structure of the J-aggregates of meso-tetrakis-(4sulphonatophenyl) porphyrins in aqueous solution [13].

In all these instances, $\pi-\pi$ lateral interaction plays the most crucial role in determining the aggregation phenomena. However, apart from the usual $\pi$-stacking interactions, one can also control the aggregation behavior through suitable substitution of the peripheral phenyl ring, as it provides an additional effect in ordering the aggregates. In order to explore such a possibility, we synthesized a new porphyrin derivative, where the peripheral phenyl rings of the tetraaryl porphyrin were substituted with a $\mathrm{C}_{16}$-alkyl chain.

In the present work, we report the aggregation behavior of this newly synthesized 5, 10, 15, 20-tetrakis-(4hexadecyloxy-phenyl)-porphyrin (P1) and its copper(II)complex (P2) in a mix-solvent system $\left(\mathrm{CH}_{2} \mathrm{Cl}_{2}-\mathrm{CH}_{3} \mathrm{OH}\right)$ with specific interest to see the effect of strong hydrophobic interactions among the long alkane chain on the structure and the spectral behavior of various aggregates. We could successfully show that the concentration of the monomer species in the final solution and the ratio of the mixing solvents are the crucial factors for determining the aggregation phenomena, which eventually lead to various nanostructures under ambient conditions.

\section{EXPERIMENTAL}

\subsection{Instrumentation}

${ }^{1} \mathrm{H}$ NMR spectra were recorded on Bruker $200 \mathrm{MHz}$ FTNMR (model: Advance-DPX 200) spectrometer, at room temperature. Chemical shifts are given in ppm. Tetramethylsilane (TMS) was used as an internal standard for all measurements. Microanalysis $(\mathrm{C}, \mathrm{H}, \mathrm{N})$ was performed using a Perkin-Elmer 4100 elemental analyzer. ESI MS measurements were carried out on Waters QTOF Micro instrument. Infrared spectra were recorded with a $\mathrm{KBr}$ pellets using Perkin Elmer Spectrum GX 2000 spectrometer and UVvisible spectral measurements were carried out with Shimadzu UV-3101 PC spectrophotometer using a quartz cell having a beam path length of $1 \mathrm{~cm}$. The surface structure of the aggregates was observed by SEM. The samples for the SEM studies were prepared on cleaned and mirror-polished brass stubs by spreading $100 \mu \mathrm{l}$ of the dispersion and evaporating the solvent in air in the dark. A LEO SEM model 1430 VP was used for the purpose. Finer details about the surface structure and shape of the aggregates were observed using a Philips CM 200 scanning-transmission electron microscope (Super twin STEM) operated at $200 \mathrm{kV}$ with the point-to-point resolution of $0.23 \mathrm{~nm}$. The samples for TEM were prepared on a 200 -mesh $\mathrm{Cu}$ grid by spreading $10-25 \mu \mathrm{L}$ of the dispersion and removing the excess solvent by sucking with a kimwipe tissue underneath the copper grid. The remaining solvent was evaporated at room temperature for four hours without exposing the film to any kind of radiation. Crystal structure of the bulk and nanostructured porphyrin was studied by using a Philip powder X-ray diffrac- tometer (Philips X'Pert MPD system) using $\mathrm{Cu} \mathrm{K} \alpha 1$ radiation $(\lambda=1.54 \AA)$.

\subsection{Materials}

All of the chemicals were obtained from commercial sources and used as received, unless mentioned otherwise. Cetyl alchohol obtained from Merck (Mumbai, India) and para-hydroxy benzaldehyde obtained from SigmaAldrich. Thionyl chloride, pyrrole, propionic acid, and $\mathrm{Cu}\left(\mathrm{CH}_{3} \mathrm{COO}\right)_{2} \cdot 2 \mathrm{H}_{2} \mathrm{O}$ were obtained from SD Fine-Chem Ltd. (Mumbai, India). Solvents for the reactions and various studies were used as received from Merck (India). Pyrrole was distilled under reduced pressure prior to use.

\subsection{Synthesis}

HexadecylChloride (1): cetyl alchohol (11.2 g, $46.1 \mathrm{mM})$ was dissolved in $60 \mathrm{~mL}$ dry chloroform in a $250 \mathrm{~mL}$ round bottom flask. Few drops of pyridine were added to this solution and the resulting solution was cooled to $10^{\circ} \mathrm{C}$. Fifteen millimeters of thionyl chloride, dissolved in $40 \mathrm{~mL}$ of chloroform was added slowly through a dropping funnel to the cooled reaction mixture. This was further diluted with another $50 \mathrm{~mL}$ of dry $\mathrm{CHCl}_{3}$ and was refluxed for 4 hours. All manipulations and reactions were performed strictly under dinitrogen gas blanket. Then little water was added and stirred for few minutes to quench the reaction. Solvent extraction was done with water and the aqueous extract was discarded. $\mathrm{CHCl}_{3}$ layer was evaporated under reduced pressure and pure compound in the form of viscous liquid was collected. Yield: $8.76 \mathrm{~g}(72 \%)$; ${ }^{1} \mathrm{HNMR}\left(200 \mathrm{M} \mathrm{Hz}, \mathrm{CDCl}_{3}\right)$ : $\delta 3.52\left(\mathrm{t}, 2 \mathrm{H}, \mathrm{J}=6.7 \mathrm{~Hz}, \mathrm{H}\left[-\mathrm{CH}_{2} \mathrm{Cl}\right]\right), 1.77(\mathrm{p}, 2 \mathrm{H}, \mathrm{J}=6.5 \mathrm{~Hz}$, $\left.\mathrm{H}\left[-\mathrm{CH}_{2}-\right]\right), 1.2(\mathrm{~b}, 30 \mathrm{H}, \mathrm{H}$ [aliphatic chain]), $0.88(\mathrm{t}, 3 \mathrm{H}$, $\left.\mathrm{J}=6.2 \mathrm{~Hz}, \mathrm{H}\left[-\mathrm{CH}_{3}\right]\right)$. FT IR $\left(\mathrm{KBr} ; v / \mathrm{cm}^{-1}\right) 2925(\mathrm{C}-\mathrm{H})$, 654(C-Cl); ES-MS: m/z $284\left(\mathrm{M}^{+}+\mathrm{Na}^{+} ; 10 \%\right), 261\left(\mathrm{M}^{+} ; 5 \%\right)$.

Parahexadecyloxybenzaldehyde (2): synthesis of the appropriate benzaldehyde derivative was achieved following literature procedure with necessary modifications $[14,15]$. $P$ hydroxy bezaldehyde $(2.01 \mathrm{~g}, 16 \mathrm{mM})$ was dissolved in $70 \mathrm{~mL}$ of dry acetonitrile in a two-necked round-bottom flask. To this solution, $\mathrm{K}_{2} \mathrm{CO}_{3}(3.3 \mathrm{~g}, 24 \mathrm{mM})$ in powder form was added and stirred for 15 minute. Long chain chloride (1) $(4.1 \mathrm{~g}, 16 \mathrm{mM})$, dissolved in $15 \mathrm{~mL}$ dry DMF, was added to the reaction mixture from a dropping funnel. KI (3.9 g, $24 \mathrm{mM}$ ) was added to the reaction mixture and finally the reaction mixture was refluxed for three days under dinitrogen atmosphere. Solution was allowed to attain the room temperature and then this was kept in freeze for 1 hour. A white precipitate was filtered off to remove the excess potassium salts and the filtrate was evaporated under vacuum. Residue was dissolved in $\mathrm{CH}_{2} \mathrm{Cl}_{2}$ and any inorganic impurity was removed in aqueous phase by solvent extraction. $\mathrm{CH}_{2} \mathrm{Cl}_{2}$ layer was collected and evaporated to yield crude product and this was subjected to column chromatography for purification. Column chromatography was carried out on silica gel (100-200 mesh) as stationary phase with $\mathrm{CHCl}_{3}$ as eluent. The first fractions were collected and evaporated. Yield: $4.1084 \mathrm{~g}$ (74\%); ${ }^{1} \mathrm{HNMR}$ (200 M hz, $\left.\mathrm{CD}_{2} \mathrm{Cl}_{2}\right): \delta 9.8(\mathrm{~s}, 1 \mathrm{H}$, 


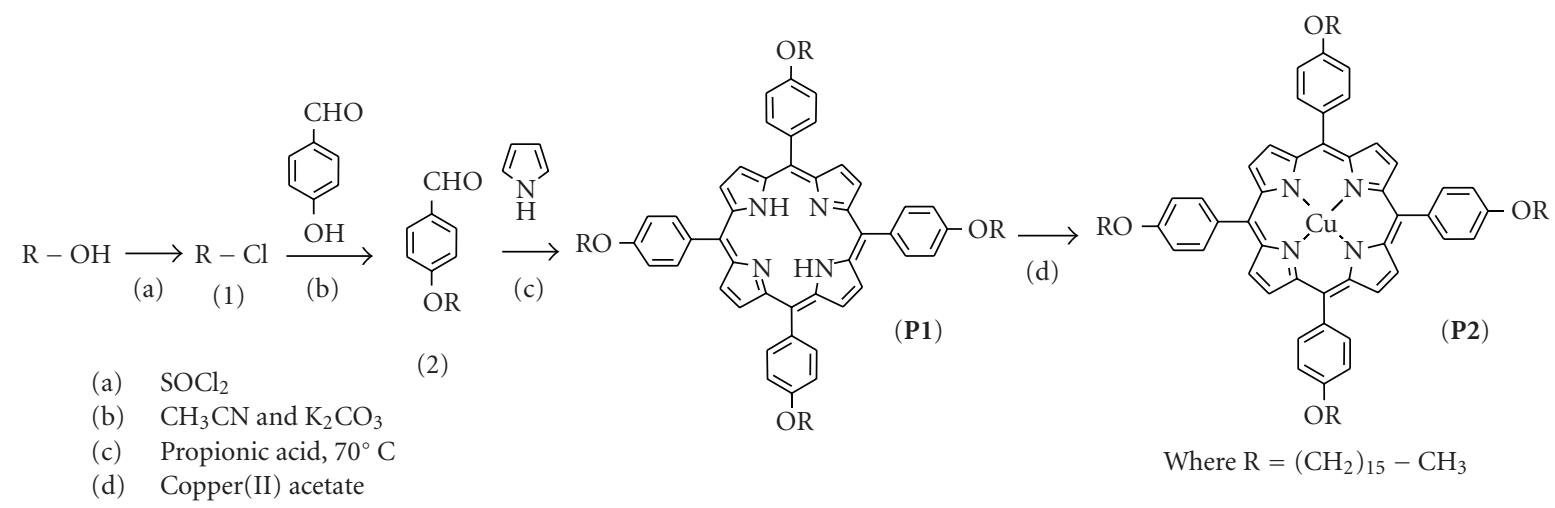

SCHEMe 1

$\mathrm{H}[-\mathrm{CHO}]), 7.8\left(\mathrm{~d}, 2 \mathrm{H}, \mathrm{J}=9 \mathrm{~Hz}, \mathrm{H}\left[\right.\right.$ phenyl $\left.\left._{2,6}\right]\right), 6.99$ (d, 2H, J $=8.6 \mathrm{~Hz}, \mathrm{H}\left[\right.$ pheny $\left.\left._{3,5}\right]\right), 4.04\left(\mathrm{t}, 2 \mathrm{H}, \mathrm{J}=6.5 \mathrm{~Hz}, \mathrm{H}\left[-\mathrm{OCH}_{2}\right]\right)$, $1.8-1.2(\mathrm{~b}, 37 \mathrm{H}, \mathrm{H}[$ aliphatic $\mathrm{H}]), .087(\mathrm{t}, 3 \mathrm{H}, \mathrm{J}=6.0 \mathrm{~Hz}$, $\left.\mathrm{H}\left[-\mathrm{CH}_{3}\right]\right)$; FT IR(KBr; v/cm $\left.{ }^{-1}\right) 2919(\mathrm{C}-\mathrm{H}), 1690(-\mathrm{CHO})$, 1602(C=C), $1509(\mathrm{C}=\mathrm{C}), 1165(\mathrm{C}-\mathrm{O}), 832(\mathrm{C}-\mathrm{H}) ; \mathrm{ES}-\mathrm{MS}: \mathrm{m} / \mathrm{z}$ $347\left(\mathrm{M}^{+}+\mathrm{H}, 15 \%\right) ; 369\left(\mathrm{M}^{+}+\mathrm{Na}^{+}, 75 \%\right)$; Elemental analysis for $\mathrm{C}_{23} \mathrm{H}_{38} \mathrm{O}_{2}$ : (calculated) $\mathrm{C} 79.76 \%, \mathrm{H} \mathrm{10.9 \%}$; (found) $\mathrm{C}$ $79.56 \%, \mathrm{H} 13.5 \%$.

5,10,15,20-tetrakis-(4-hexadecyloxy-phenyl)-porphyrin(P1): synthesis of the compound P1 was achieved following procedure mentioned in the literatures with necessary modifications [16]. Freshly distilled pyrrole $(0.4 \mathrm{~mL}, 4.3 \mathrm{mM})$ was slowly added under stirring to a solution of $p$ hexadecyloxybenzaldehyde (2) (2 g, $5.7 \mathrm{mM})$ in $60 \mathrm{~mL}$ of refluxing propionic acid. Refluxing was continued for 4 hours and then the reaction mixture was cooled to room temperature. Shiny purple crystalline product was precipitated. It was filtered, washed thoroughly with hot water, and dried Yield: $440 \mathrm{mg}$ (49\%); ${ }^{1} \mathrm{HNMR}\left(200 \mathrm{MHz}, \mathrm{CD}_{2} \mathrm{Cl}_{2}\right): \delta 8.86$ (s, $8 \mathrm{H}, \beta$ pyrrole $), 8.064\left(\mathrm{~d}, 8 \mathrm{H}, \mathrm{J}=8.6 \mathrm{HzH}\left[\right.\right.$ phenyl $\left.\left._{2,6}\right]\right), 7.22(\mathrm{~d}$, $8 \mathrm{H}, \mathrm{J}=8.4 \mathrm{~Hz}, \mathrm{H}\left[\right.$ phenyl $\left.\left._{3,5}\right]\right), 4.18(\mathrm{t}, 8 \mathrm{H}, \mathrm{J}=6.4 \mathrm{~Hz}, \mathrm{H}[-$ $\left.\left.\mathrm{OCH}_{2}\right]\right) ; 1.8-1.2(\mathrm{~b}, 125 \mathrm{H}, \mathrm{H}[$ aliphatic $\mathrm{H}]), 0.87(\mathrm{t}, 12 \mathrm{H}$, $\left.\mathrm{J}=5.8 \mathrm{~Hz}, \mathrm{H}\left[-\mathrm{CH}_{3}\right]\right),-2.7(\mathrm{~b}, 2 \mathrm{H}, \mathrm{NH}) ; \mathrm{UV}$-vis $\left(\mathrm{CH}_{2} \mathrm{Cl}_{2}\right.$; $\lambda / \mathrm{nm}$; (loge/ $\left.\left.\mathrm{M}^{-1} \mathrm{~cm}^{-1}\right)\right): 421$ (5.49), 518 (4.24), 556 (4.12), 595 (3.86), 696 (4.00); FT IR $\left(\mathrm{KBr} ; v / \mathrm{cm}^{-1}\right)$ 2921(C-H), 1604(C=C), $1507(\mathrm{C}=\mathrm{C}), 1173(\mathrm{C}-\mathrm{O}), 802(\mathrm{C}-\mathrm{H})$; elemental analysis: calculated for $\mathrm{C}_{108} \mathrm{H}_{158} \mathrm{~N}_{4} \mathrm{O}_{4}$ : $\mathrm{C} 82.44, \mathrm{H}$ 9.92, $\mathrm{N}$ $3.56 \%$, found: C 81.5, H 10.1, N 3.4\%.

5,10,15,20-tetrakis(4-(hexadecyloxy)phenyl)-copper(II)porphyrin (P2): copper(II) acetate $(0.031 \mathrm{gm}, 0.152 \mathrm{mM})$ was dissolved in minimum volume of acetonitrile in a $100 \mathrm{~mL}$ in two-necked round-bottom flask, then $20 \mathrm{~mL}$ of toluene was added. To this solution, 5,10,15,20-tetrakis-(4-hexadecyloxy-phenyl)-porphyrin (P1; $60 \mathrm{mg}, 0.038 \mathrm{mM})$, dissolved in minimum volume of toluene, was added with stirring and was refluxed for 5 hours. Then this reaction mixture was stirred at room temperature for 18 hours and dried under reduced pressure. Solid residue was dissolved in minimum volume of $\mathrm{CHCl}_{3}$ and subjected to gravity chromatography for purification using silica gel (100-200 meshes) as stationary phase and $\mathrm{CHCl}_{3} / \mathrm{n}$-hexane $(3: 7 ; \mathrm{v} / \mathrm{v})$ as eluent. The first fractions were collected and evaporated to get the desired product. Yield: $70 \mathrm{mg}(90 \%)$; UV- vis $\left(\mathrm{CH}_{2} \mathrm{Cl}_{2} ; \lambda / \mathrm{nm}\right.$ $\left.\left(\log \varepsilon / \mathrm{M}^{-1} \mathrm{Cm}^{-1}\right)\right): 418$ (5.48), 541 (4.19), 580 (2.5); FTIR $\left(\mathrm{KBr} ; v / \mathrm{cm}^{-1}\right.$ ) 2921(C-H), 1605 (C=C), 1504 (C=C), 1174 (C-O), 802 (C-H); ES-MS: m/z $1636\left(\mathrm{M}^{+}, 18 \%\right)$; elemental analysis: calculated for $\mathrm{C}_{108} \mathrm{H}_{156} \mathrm{~N}_{4} \mathrm{O}_{4} \mathrm{Cu}$ : C 79.19, h 9.6, N 3.4\%, found: C 78.6, H 9.5\%, N 3.3\%.

\section{RESULTS AND DISCUSSION}

\subsection{Synthesis of $P 1$ and $P 2$}

Appropriate benzaldehyde derivative (2) was synthesized by reacting cetyl chloride (1) with the $p$-hydroxy benzaldehyde in presence of $\mathrm{K}_{2} \mathrm{CO}_{3}$ as base. This benzaldehyde derivative was allowed to react with equimolar amount of freshly distilled pyrroles for the synthesis of the desired porphyrin derivative P1 (Scheme 1). This was further used for reaction with $\mathrm{Cu}$ (II)-acetate for synthesis of $\mathrm{Cu}$ (II)-porphyrin complex (P2). Analytical data for isolated ligands $\mathbf{P 1}$ and the $\mathrm{Cu}$ (II)-porphyrin complex (P2) supports the formulation proposed for these molecules.

\subsection{Aggregation of P1}

$0.3 \mathrm{~mL} 0.7 \mathrm{mM}$ solution of $\mathbf{P 1}$ in $\mathrm{CH}_{2} \mathrm{Cl}_{2}$ was taken in a small glass beaker (volumetric capacity of $20 \mathrm{~mL}$ ). To the homogeneous solution, $5 \mathrm{~mL}$ of spectroscopic grade methanol was added very fast under continuous magnetic stirring at $25^{\circ} \mathrm{C}$ and atmospheric pressure. The solution became opaque immediately. The dispersion was then kept under continuous magnetic stirring for 1 hour using rice-type magnetic needle. Finally the dispersion was kept in dark. In another experiment, $10 \mathrm{~mL}$ of spectroscopic grade methanol was added to $0.3 \mathrm{~mL} 0.7 \mathrm{mM}$ solution of $\mathbf{P 1}$ in $\mathrm{CH}_{2} \mathrm{Cl}_{2}$ in a $20 \mathrm{~mL}$ glass beaker at $25^{\circ} \mathrm{C}$ following the similar process as above.

\subsection{Aggregation of $P 2$}

$1 \mathrm{~mL} 5 \mu \mathrm{M}$ solution of $\mathbf{P} 2$ in $\mathrm{CH}_{2} \mathrm{Cl}_{2}$ was taken in a small glass beaker (volumetric capacity of $20 \mathrm{~mL}$ ). Two millimeters of spectroscopic grade methanol was added to the clear homogeneous solution under continuous magnetic stirring 


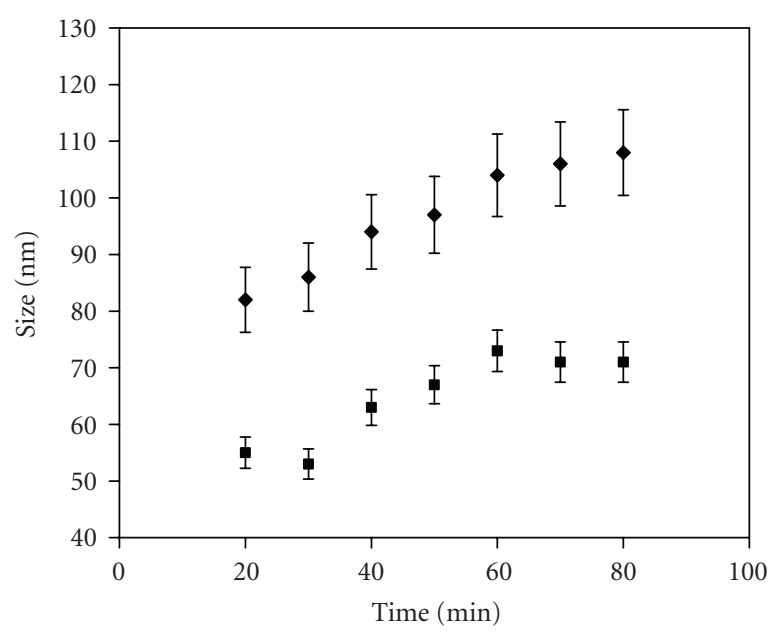

(a)

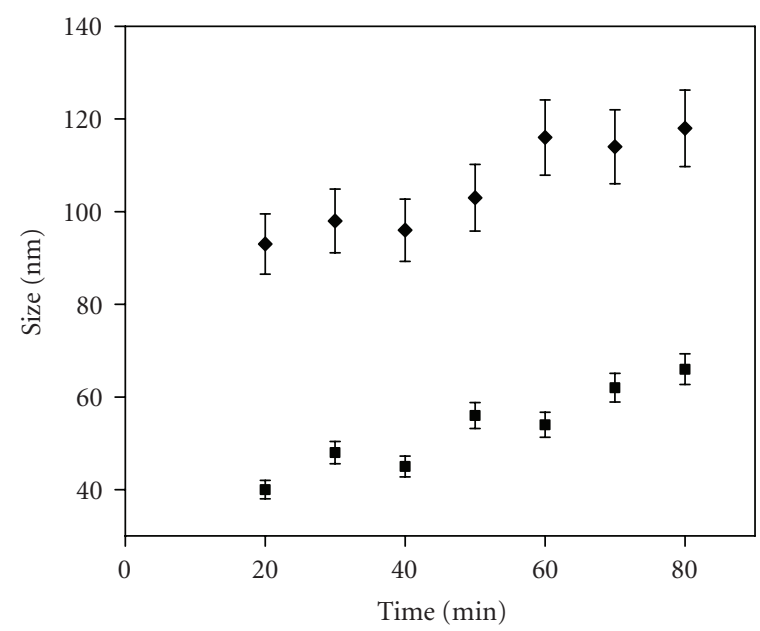

(b)

FIgURE 1: Growth profile of (a) free porphyrin (P1) base obtained at a solvent ratio of $1: 34(\mathrm{v} / \mathrm{v})$ and (b) Cu porphyrin complex (P2) at a solvent ratio of $1: 4\left(\mathrm{CH}_{2} \mathrm{Cl}_{2}: \mathrm{CH}_{3} \mathrm{OH}\right)$ at $(\boldsymbol{\square}) 298 \mathrm{~K}$ and $(\boldsymbol{)})$ $323 \mathrm{~K}$, particle size obtained from STEM studies.

at $25^{\circ} \mathrm{C}$ and atmospheric pressure. Afterwards, $50 \mu \mathrm{L}$ of triethylene glycol monomethyl ether was added for preventing agglomeration. The dispersion was kept under magnetic stirring for 30 minutes. Finally the dispersion was kept in dark. Following the same approach, in a second experiment, $1 \mathrm{~mL} 5 \mu \mathrm{M}$ solution of $\mathbf{P} 2$ in $\mathrm{CH}_{2} \mathrm{Cl}_{2}$ was mixed with $4 \mathrm{~mL}$ of methanol.

\subsection{Growth studies of the aggregates}

The rate of growth of the nanostructured $\mathbf{P} 1$ and $\mathbf{P} 2$ was carried out after 20 minutes of addition of methanol solvent. The growth profile of $\mathbf{P 1}$ at two different temperatures for a predetermined optimum solvent ratio $(1: 34)$ is shown in Figure 1(a). It can be seen that the size of the nanocrystals of $\mathbf{P 1}$ increases faster in the initial phase of reprecipitation process both at room temperature and elevated temperature. However after 70 minutes, the particle size reaches the maximum after which no further growth in the size of the nanoparticles takes place. But, the rate of growth at the elevated temperature is relatively high. In the case of $\mathbf{P} 2$, it can be seen from Figure 1(b) that the trend of growth at a solvent ratio of $1: 4$ is similar to that of $\mathbf{P} \mathbf{1}$. Since we are interested to generate nanostructures of $\mathbf{P} \mathbf{1}$ and $\mathbf{P} 2$, we restrict our studies to room temperature. This helps us to neglect the kinetic complications such as the diffusion of the particles, change of viscosity of the reaction media, and thereby mobility of the monomer units. Thus, we could attribute the process of formation of nanostructures mostly to the thermodynamic parameters of the reprecipitation process.

\subsection{Characterizations of the aggregates}

It can be seen from Figure 2(a) that the crystal structures of the bulk and nanostructured P1 obtained at a solvent ratio of 1 : 34 remain unaltered. However, nanostructured P2, prepared at a solvent ratio of $1: 4$, shows amorphous nature which is presented in Figure 2(b). The SEM image of the bulk aggregate of free porphyrin (P1) base is presented in Figure 3(a). This reveals that the surface of the aggregates is rough with a lot of steps and defects. The individual agglomerate is of circular disc shape with a diameter more than micron. Change in the solvent ratio from $1: 17(\mathrm{v} / \mathrm{v})$ to $1: 34$ (v/v) $\left(\mathrm{CH}_{2} \mathrm{Cl}_{2}: \mathrm{CH}_{3} \mathrm{OH}\right)$ does not alter the surface of the agglomerate to an observable extent, except the appearance of the giant aggregates. The aggregate looks like flower with enhanced defect density due to weak interconnectivity among the individuals (Figure 3(b)).

The aggregates of copper (II)-complex (P2), on the contrary, exhibit smooth surface indicating strong connectivity among the particles (Figure 4(a)). The size of the agglomerates varies in the range of 2-5 microns. However, significant change in the surface of the aggregates of $\mathbf{P 2}$ is observed as the solvent $\left(\mathrm{CH}_{2} \mathrm{Cl}_{2}-\mathrm{CH}_{3} \mathrm{OH}\right)$ ratio changed from $1: 2$ to 1 : 4 and surface seemed to be covered by fiber or tubular structure having diameter in the nanometer length scale with a rough appearance (Figure $4(\mathrm{~b})$ ).

The TEM image of the individual aggregate of $\mathbf{P 1}$, obtained at a solvent ratio of $1: 34$, is presented in Figure 5(a). Majority of the aggregates are either of particulate form or of tubular morphology. The particle size varies in a broad range of 30-125 nm. It is noted from Figure 5(a) that the tube and/or rod shape nanostructures is formed at the periphery of the giant aggregate. Figure 5(b) shows another TEM image of the tubes in relatively higher resolution in a different domain of the grid.

The outer diameter of the tubes is in the range of 50$60 \mathrm{~nm}$ with the internal diameter varied in the range of 10$15 \mathrm{~nm}$. Figure 5(b) also reveals that the end of the nanotubes is closed. The tubes are observed in a giant agglomerate form indicating presence of strong cohesive force among them. As the solvent ratio is changed from $1: 34$ to $1: 17$, formation of only nanoparticles with particle size varying in the narrow range of $2-5 \mathrm{~nm}$ (Supporting Information (SI) Figure 1) is observed. However, these particles tend to remain as giant agglomerate without undergoing any kind of organization process. In the case of $\mathbf{P} 2$, at a solvent ratio of $1: 2$, major- 


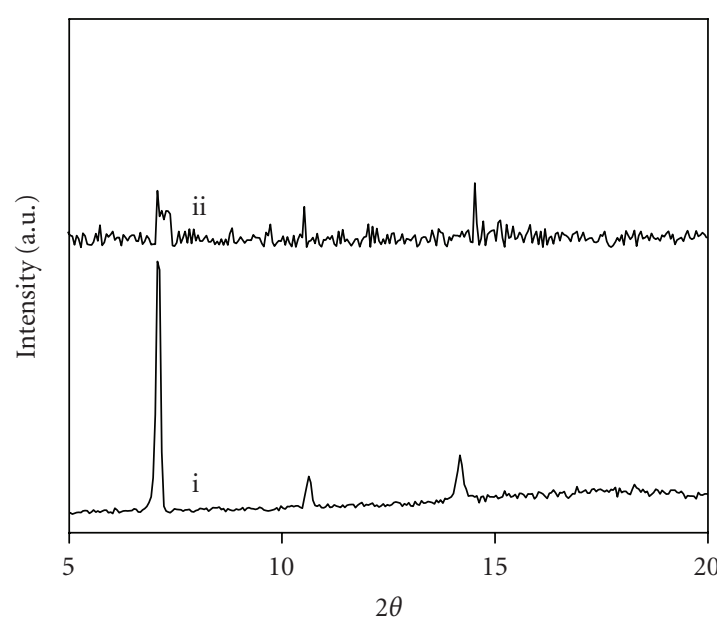

(a)

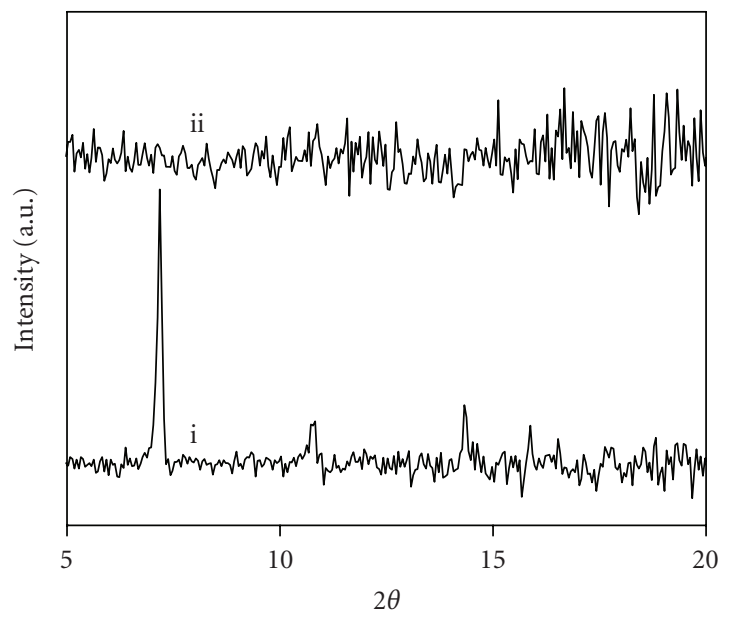

(b)

FIgure 2: Powder XRD pattern of (a) bulk (i) and nanostructured (ii) free porphyrin $(\mathbf{P 1})$ base obtained at solvent ratio of $1: 34(\mathrm{v} / \mathrm{v})$ $\left(\mathrm{CH}_{2} \mathrm{Cl}_{2}: \mathrm{CH}_{3} \mathrm{OH}\right)$ at $298 \mathrm{~K}$ and (b) bulk (i) and nanostructured (ii) metal porphyrin complex (P2), prepared at a solvent ratio of $1: 4$.

ity of the aggregates form nanoparticles with deformed cube (diamond) shape (SI Figure 2). The particle size varies in the range of 100-300 $\mathrm{nm}$. The nanoparticles do not undergo any kind of organization in the mix-solvent environment. However, as the solvent ratio is changed from $1: 2$ to $1: 4(\mathrm{v} / \mathrm{v})$, organization of the aggregates of $\mathbf{P} 2$ led to a bamboo-type structure (Figure 6), that is, tubular morphology with closed end tube inside. The outer diameters of the tubes are in the range of $50-75 \mathrm{~nm}$ with very thin wall $(<5 \mathrm{~nm})$. The distance between two successive knots (closed end tubes) inside the tube is in the range of $150-200 \mathrm{~nm}$ (viewed along the horizontal axis).

Physical observations as well as spectroscopic evidence (UV-visible-NIR spectra) confirmed stability of the dispersions over a period of three to four months. The formation of various nanostructures from the organization of the aggregates could be attributed to strong $\pi-\pi$ interactions

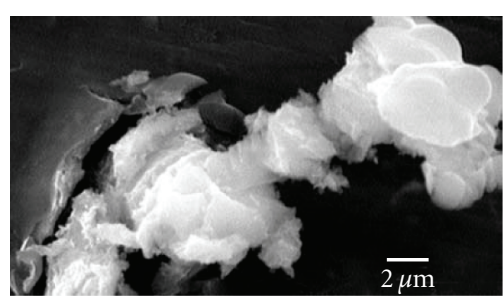

(a)

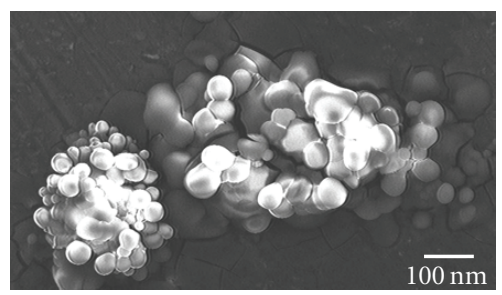

(b)

FIGURE 3: SEM image of the bulk aggregate of free porphyrin (P1) base at solvent ratios of (a) $1: 34(\mathrm{v} / \mathrm{v})$ and (b) $1: 17(\mathrm{v} / \mathrm{v})$ $\left(\mathrm{CH}_{2} \mathrm{Cl}_{2}: \mathrm{CH}_{3} \mathrm{OH}\right)$.

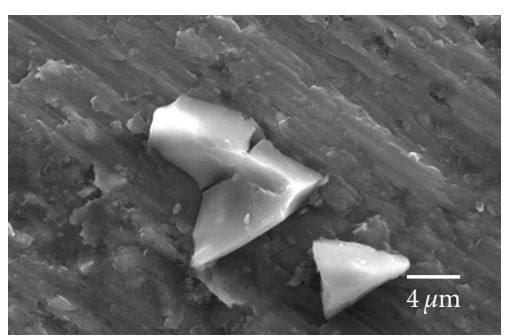

(a)

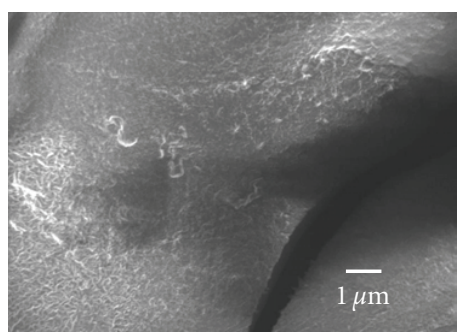

(b)

FIGURE 4: SEM image of the bulk aggregate of Cu complex (P2) at solvent ratios of (a) $1: 2(\mathrm{v} / \mathrm{v})$ and (b) $1: 4(\mathrm{v} / \mathrm{v})\left(\mathrm{CH}_{2} \mathrm{Cl}_{2}: \mathrm{CH}_{3} \mathrm{OH}\right)$.

among the phenyl-substituted tetrapyrrole core, as well as hydrophobic interaction among the long alkane chains.

The UV-visible spectra of $\mathbf{P 1}$ in $\mathrm{CH}_{2} \mathrm{Cl}_{2}$ and the nanodispersion are presented in Figure 7. The homogenous solution of $\mathbf{P 1}$ in $\mathrm{CH}_{2} \mathrm{Cl}_{2}$ reveals an allowed Soret band at $422 \mathrm{~nm}$ and quasiallowed Q-bands, signifying the $\mathrm{D}_{2 \mathrm{~h}}$ symmetry. In case of spectra recorded for the self-aggregates of P1, the Soret band position remains unaltered, but a new band appears at $456 \mathrm{~nm}$ along with the usual Q-bands. The new band can be attributed to the partial J-aggregation in the self-aggregates [4]. 


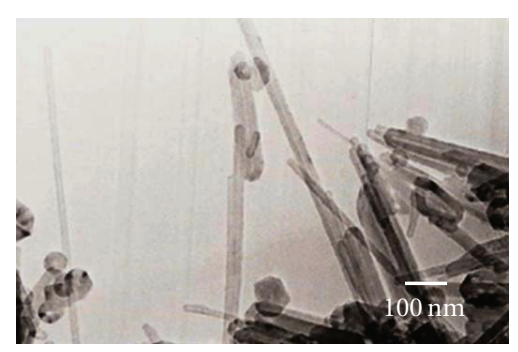

(a)

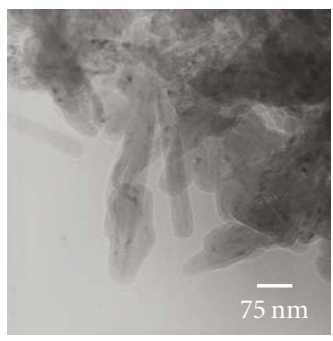

(b)

FIGURE 5: TEM of the aggregates of free porphyrin base (P1) prepared at a solvent ratio of $1: 34(\mathrm{v} / \mathrm{v})\left(\mathrm{CH}_{2} \mathrm{Cl}_{2}: \mathrm{CH}_{3} \mathrm{OH}\right)$ showing (a) tubes and rod shapes and (b) tubes in higher resolution.

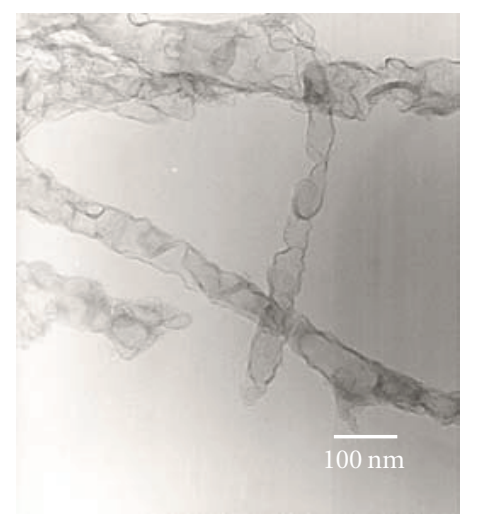

Figure 6: TEM of the individual aggregates of copper complex (P2) prepared at a solvent ratio of $1: 4(\mathrm{v} / \mathrm{v})\left(\mathrm{CH}_{2} \mathrm{Cl}_{2}: \mathrm{CH}_{3} \mathrm{OH}\right)$.

Dispersion of nanoparticles of $\mathbf{P} \mathbf{1}$ exhibits the Soret band at $444 \mathrm{~nm}$, which is red shifted by $22 \mathrm{~nm}$ from the corresponding homogeneous solution with an additional band at $400 \mathrm{~nm}$. Thus the UV-visible spectra recorded for the nano dispersion shows the formation of J-aggregates with insignificant formation of $\mathrm{H}$-aggregates as evidenced by the blue-shifted $\mathrm{H}$-band at $400 \mathrm{~nm}$ [4]. The important point to note here is the broad width of the characteristics absorption bands of the nano dispersion. This may be correlated to the coherent coupling of the transition dipoles of fewer numbers of molecules than generally predicted for normal J-aggregates [17]. We may also correlate the broad J-band to the presence of large disordered domains induced by the nonpolar interactions among the long alkyl chains in the nanotubes [4]. As the solvent ratio changed from $1: 34$ to

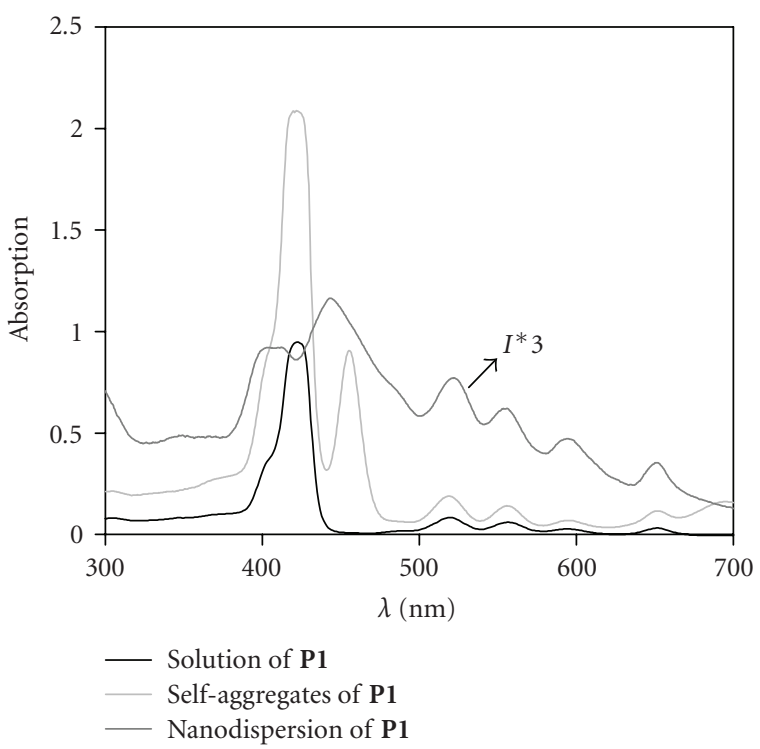

FIgURE 7: Normalized UV-visible absorption spectra of various nanostructured aggregates (at a solvent ratio of $1: 34(\mathrm{v} / \mathrm{v})$ $\left(\mathrm{CH}_{2} \mathrm{Cl}_{2}: \mathrm{CH}_{3} \mathrm{OH}\right)$ ) of $\mathbf{P 1}$ (intensity is enhanced by three times for nanodispersion of $\mathbf{P 1}$ ).

$1: 17(\mathrm{v} / \mathrm{v})$, a prominent red shift (at $442 \mathrm{~nm}$ ) of relatively Sharper Soret band is observed. Besides the soret band, weak $\mathrm{H}$-band at $400 \mathrm{~nm}$ and weak monomer peak at $410 \mathrm{~nm}$ along with the quasiallowed Q-bands (SI Figure 3) are also observed. The sharp J-band could be an indication of involvement of higher number of monomer units in the aggregates.

The nature of the absorption spectra for $\mathbf{P} 2$ in $\mathrm{CH}_{2} \mathrm{Cl}_{2}$ is indicative of the $\mathrm{D}_{4 \mathrm{~h}}$ symmetry, characteristics of porphyrin coordinated to metal ion through four $\mathrm{N}$ heteronuclear [1]. The nanostructure, obtained from the $\mathbf{P} 2$ at a solvent ratio of $1: 4$, shows red-shifted broad Soret band at $453 \mathrm{~nm}$ with very broad Q-band (Figure 8). The Soret band is found to be little blue shifted in the absorption spectra of the nano dispersion of $\mathbf{P 2}$ compared to the homogeneous solution. The absorption band clearly indicates that J-aggregation is dominant in the dispersion of $\mathbf{P} \mathbf{2}$ with very few $\mathrm{H}$-aggregates. The broad bands, as evident from Figure 6, can be correlated to the disordered moiety in the nanostructures due to strong hydrophobic interactions among the alkane chain [4]. Spectrum for the $\mathbf{P} 2$, at the solvent ratio of $1: 2$, shows absorption of monomer with little contribution from J-aggregates.

It is thus observed that the aggregates of $\mathbf{P} \mathbf{1}$ and $\mathbf{P} 2$ are dominated by the face-to-face arrangement of the monomer units (J-aggregates). However, the solvent ratio plays an important role in dictating the organization of the aggregates. In both cases of $\mathbf{P} \mathbf{1}$ and $\mathbf{P} 2$, the organization of the nanoaggregates to particular nanostructures took place at higher solvent ratio, that is, the lower concentration of the monomeric species. 


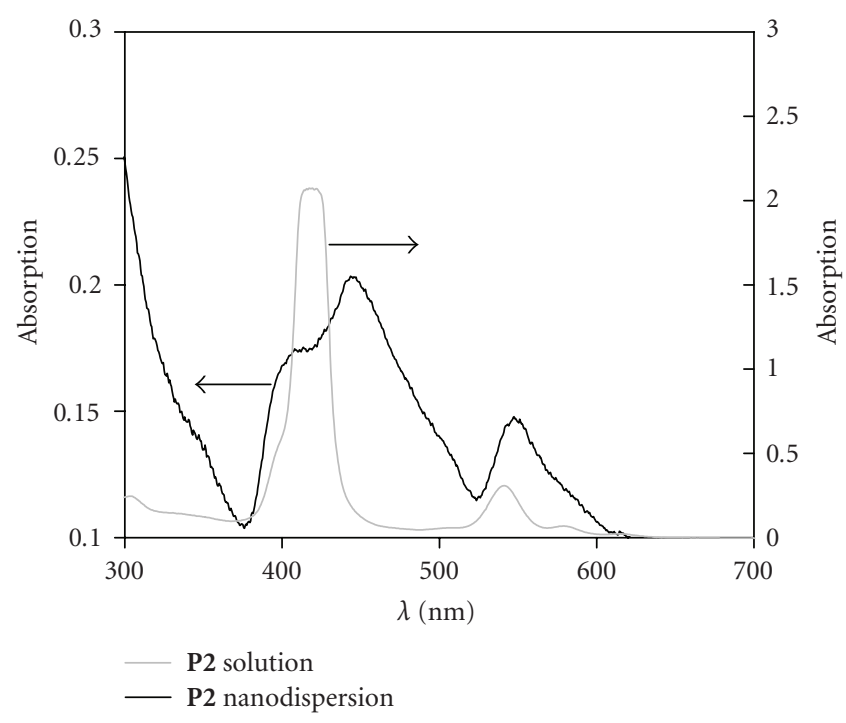

FIgURE 8: Normalized UV-visible absorption spectra of P2 (the dispersion of $\mathbf{P} 2$ is obtained at a solvent ratio of $1: 4(\mathrm{v} / \mathrm{v})$ $\left.\left(\mathrm{CH}_{2} \mathrm{Cl}_{2}: \mathrm{CH}_{3} \mathrm{OH}\right)\right)$.

\section{CONCLUSIONS}

We have shown the aggregation behavior of free porphyrin substituted with $\mathrm{C}_{16}$-alkyl chain on the peripheral phenyl ring (P1) and its corresponding $\mathrm{Cu}$ (II)-complex (P2) in mixsolvent system. It was noted that the free porphyrin ligand underwent aggregation to yield different type of aggregates at various ratios of the mixing solvents. At a solvent ratio of $1: 34$, formation of nanorods and nanotubes occurred. As the solvent ratio was changed to $1: 17$, formation of nanoparticles was observed. Thus at a certain concentration of the monomer, it is seemed that the extended intermolecular and interparticle hydrophobic interactions, besides usual $\pi$-stacking effect, $\mathrm{H}$-bonding, and other weak interactions, lead to the formation of organized nanostructures. XRD results indicated the same crystal structure for the bulk and nano-free porphyrin, P1 which was obtained at a solvent ratio of $1: 34$. Red-shifted broad Sorret bands in the UV-visible spectra of the nanostructured free porphine base indicate that JJ aggregation takes place predominantly among the monomer units. The UV-visible bands of the organized nano-aggregates were broader than the corresponding bulk solution indicating involvement of few numbers of monomers for the generation of the aggregates. Detailed work is in progress to see the specific effect of $\mathrm{pH}$, temperatures, and ionic strength on the formation of nanoparticles and their organization.

\section{ACKNOWLEDGMENTS}

This work is supported by Council of Scientific and Industrial Research (CSIR), Department of Science and Technology (DST), and Board of Research in Nuclear Science (BRNS), Government of India. D. A. Jose wishes to acknowl- edge CSIR for a Senior Research Fellowship. A. Das and I. Mukhopadhyay wish to thank Dr. P. K. Ghosh (CSMCRI, Bhavnagar) for his keen interest in this work.

\section{REFERENCES}

[1] D. L. Akins, H.-R. Zhu, and C. Guo, "Aggregation of tetraarylsubstituted porphyrins in homogeneous solution," Journal of Physical Chemistry, vol. 100, no. 13, pp. 5420-5425, 1996.

[2] P. W. Bohn, "Aspects of structure and energy transport in artificial molecular assemblies," Annual Review of Physical Chemistry, vol. 44, no. 1, pp. 37-60, 1993.

[3] P. Kubát, K. Lang, K. Procházková, and P. Anzenbacher Jr., "Self-aggregates of cationic meso-tetratolylporphyrins in aqueous solutions," Langmuir, vol. 19, no. 2, pp. 422-428, 2003.

[4] N. C. Maiti, S. Mazumdar, and N. Periasamy, "J- and Haggregates of porphyrin-surfactant complexes: time-resolved fluorescence and other spectroscopic studies," Journal of Physical Chemistry B, vol. 102, no. 9, pp. 1528-1538, 1998.

[5] A. S. R. Koti and N. Periasamy, "Self-assembly of templatedirected J-aggregates of porphyrin," Chemistry of Materials, vol. 15, no. 2, pp. 369-371, 2003.

[6] X. Gong, T. Milic, C. Xu, J. D. Batteas, and C. M. Drain, "Preparation and characterization of porphyrin nanoparticles," Journal of the American Chemical Society, vol. 124, no. 48, pp. 14290-14291, 2002.

[7] L. Qi, H. Cölfen, and M. Antonietti, "Synthesis and characterization of CdS nanoparticles stabilized by double-hydrophilic block copolymers," Nano Letters, vol. 1, no. 2, pp. 61-65, 2001.

[8] R. Yerushalmi, A. Scherz, and M. E. van der Boom, "Enhancement of molecular properties in thin films by controlled orientation of molecular building blocks," Journal of the American Chemical Society, vol. 126, no. 9, pp. 2700-2701, 2004.

[9] Z. Wang, C. J. Medforth, and J. A. Shelnutt, "Porphyrin nanotubes by ionic self-assembly," Journal of the American Chemical Society, vol. 126, no. 49, pp. 15954-15955, 2004.

[10] H.-R. Chung, E. Kwon, H. Oikawa, H. Kasai, and H. Nakanishi, "Effect of solvent on organic nanocrystal growth using the reprecipitation method," Journal of Crystal Growth, vol. 294, no. 2, pp. 459-463, 2006.

[11] T. Tachikawa, H. chung, A. Masuhara, et al., "In situ and ex situ observations of the growth dynamics of single perylene nanocrystal in water," Journal of American Chemical Society, vol. 128, no. 50, pp. 15944-15945, 2006.

[12] B. Liu, D.-J. Qian, M. Chen, T. Wakayama, C. Nakamura, and J. Miyake, "Metal-mediated coordination polymer nanotubes of 5,10,15,20-tetrapyridylporphine and tris(4-pyridyl)-1,3,5triazine at the water-chloroform interface," Chemical Communications, no. 30, pp. 3175-3177, 2006.

[13] Y. Kitahama, Y. Kimura, and K. Takazawa, "Study of internal structure of meso-tetrakis (4-Sulfonatophenyl) porphine J-aggregates in solution by fluorescence microscope imaging in a magnetic field," Langmuir, vol. 22, no. 18, pp. 7600-7604, 2006.

[14] G. W. Gray and B. Jones, "Mesomorphism and chemical constitution-part II: the trans-p-n-alkoxycinnamic acids," Journal of Chemical Society, vol. 2, pp. 1467-1470, 1954.

[15] A. C. Benniston, P. Gunning, and R. D. Peacock, "Synthesis and binding properties of hybrid cyclophane-azamacrocyclic receptors," Journal of Organic Chemistry, vol. 70, no. 1, pp. 115-123, 2005. 
[16] A. P. H. J. Schenning, D. H. W. Hubert, M. C. Feiters, and R. J. M. Nolte, "Control of aggregation and tuning of the location of porphyrins in synthetic membranes as mimics for cytochrome P450," Langmuir, vol. 12, no. 6, pp. 1572-1577, 1996.

[17] A. S. R. Koti, J. Taneja, and N. Periasamy, "Control of coherence length and aggregate size in the J-aggregate of porphyrin," Chemical Physics Letters, vol. 375, no. 1-2, pp. 171-176, 2003. 

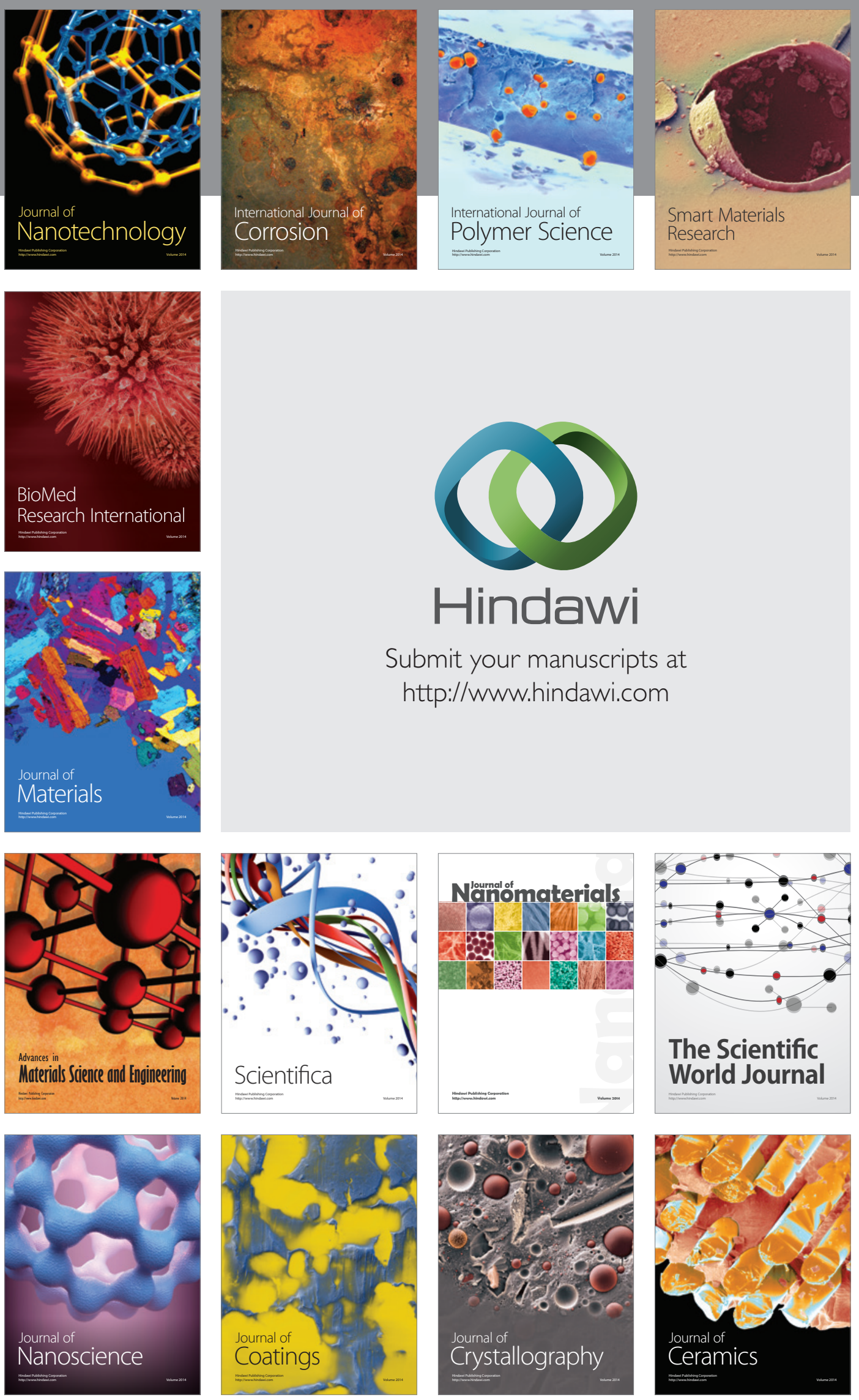

The Scientific World Journal

Submit your manuscripts at

http://www.hindawi.com

\section{World Journal}

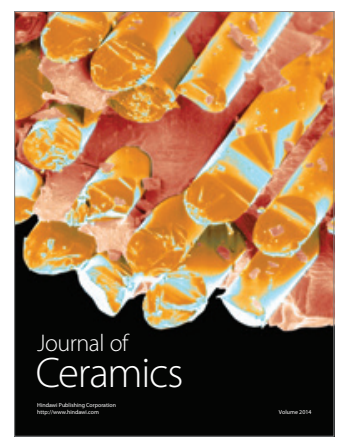

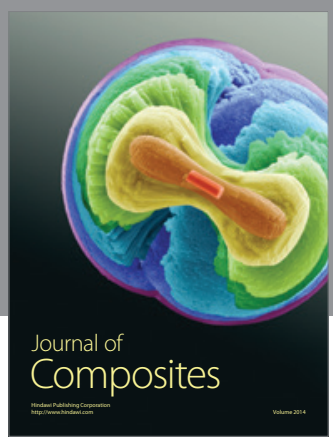
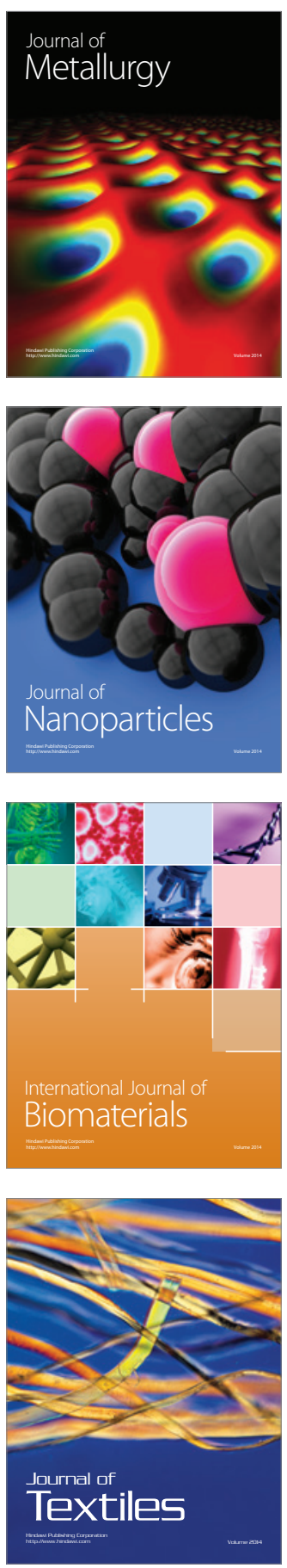